ISSN: 2617-6548

\title{
Impact Energy Absorption Capability of Polygonal Cross-Section Thin-Walled Beams under
}

\section{Lateral Impact}

\author{
(D) Sanjay Patil ${ }^{* *}$, (D)Arvind Bhosale 2 , (DVijaypatil Dhepe ${ }^{3}$, (D) Dheeraj Lengare ${ }^{4}$, (D) Ravi Kakde ${ }^{5}$ \\ 1,2,3,4,5 Assistant Professor, Department of Automobile Engineering, Government College of Engineering and Research, Avasari (kh), \\ Pune, Maharashtra, India. \\ *Corresponding author: Sanjay Patil (sdpatil.auto@gcoeara.ac.in)
}

\begin{abstract}
The continuing efforts of automotive technology aim to deliver even greater safety benefits and reduce the weight of a vehicle. Thin-walled beams (TWB) are widely used as strengtheners or energy absorbers in vehicle bodies due to their lightweight and excellent energy absorption capacity. Thus, researchers are interested in the collapse behaviour and mechanical properties of thin-walled beams under static and dynamic loadings. Circular TWB is commonly used in vehicle side doors. In the event of a side collision, this beam deforms and absorbs the greatest amount of impact energy. In this study, the energy absorption capability and crashworthiness of polygonal cross-section TWBs subjected to lateral impact was investigated using numerical simulations. Polygonal TWB ranging from square to dodecagon, as well as circular cross section, were selected for this study. Energy absorption (EA), specific energy absorption (SEA) and crash force efficiency (CFE) crashworthiness indicators are employed to evaluate the bending collapse performance. Because TWB thickness and weight have a greater impact on bending performance, they were kept constant across all polygons. In ABAQUS explicit dynamic software, finite element simulations are performed, and plastic hinges and flattening patterns of all polygons are examined. The results show that heptagon, octagon, and nonagon cross-section TWB perform better in crashworthiness than square and circular TWB.
\end{abstract}

Keywords: Energy absorption, Specific energy absorption, Bending collapse, Crashworthiness, Crash force efficiency, Thin wall tube, Polygonal cross-section.

DOI: 10.53894 /ijirss.v4i4.96

Funding: This study received no specific financial support.

History: Received: 14 May 2021/Revised: 18 June 2021/Accepted: 3 August 2021/Published: 9 September 2021

Licensed: This work is licensed under a Creative Commons Attribution 4.0 License $($ (c) $)$ EY

Acknowledgement: All authors contributed to the conception and design of the study.

Competing Interests: The authors declare that they have no conflict of interests.

Transparency: The authors confirm that the manuscript is an honest, accurate, and transparent account of the study was reported; that no vital features of the study have been omitted; and that any discrepancies from the study as planned have been explained.

Ethical: This study follows all ethical practices during writing.

\section{Introduction}

Thin-walled beams are widely used for crashworthiness applications due to their advantages of low price, lightweight, high strength and stiffness, and excellent energy absorption capacity [1]. TWBs are commonly employed in automobiles, special purpose vehicles, roll-over and falling object protective structures, and other areas subjected to safety requirements 
$[1,2]$. At the time of impact, the beam deforms and absorbs a significant amount of energy [2, 3]. TWBs are available in a wide range of cross-sections, including round, rectangular, square, and elliptical $[4,5]$. There are various theories that are popular to understand the collapse behaviour of thin-wall tubes during lateral loading to evaluate strength and energy absorption characteristics. Brazier first pointed out the flattening associated with the bending deformation of a cylinder. The cross-section of a beam flattens as the deformation progresses when it is subjected to lateral loading. As the crosssection flattens, the bending stiffness of the beam decreases, the relationship between crush force and deformation becomes nonlinear, and the beam deforms largely as a result of the imposed crush force [6, 7]. Flattening patterns are studied experimentally and theoretically by many researchers, including Abramowicz [8]; Saadatfard, et al. [9]. According to analytical and experimental research by Kecman [10] for square and rectangular tubes, when a thin wall beam is subjected to a bending load, the cross-section starts to deform plastically. These plastic deformations occur over some folding lines, which are called "hinge lines". The progression of plastic hinge movement drives the crashworthiness performance of the circular beam. Many researchers have used this hinge line model and found good agreement between numerical and experimental results, including Poonaya, et al. [11]; Elchalakani, et al. [12]; Aljibori, et al. [13]. Kotelko, et al. [14] investigated the yield line mechanism (YLM) model of rectangular and trapezoidal box section beams. These models of the YLM are based on experimental findings. Plastic folding of the cross-section walls occurs when thin-walled parts collapse under lateral impact. The TWB strength and energy absorption capacity can be evaluated using a bending moment-rotation relationship obtained from the YLM study of the collapse mechanism. Maduliat, et al. [15] examined steel hollow sections using the YLM model and found that the YLM collapse curves are in good agreement with the real experiment graphs.

Crashworthiness indicators are used to compare the crashworthiness of different thin-wall tubes with varying crosssections, thicknesses, diameters, materials, and so on. Energy Absorption (EA), Specific Energy Absorption (SEA), average crash force $\left(\mathrm{F}_{\mathrm{avg}}\right)$ and Crash Force Efficiency $(\mathrm{CFE})$ are crashworthiness indicators [7, 9].

EA indicator is used to estimate the total energy absorbing capacity of a TWB and it is evaluated by calculating the area under the force displacement curve of the bending process. A higher EA value implies that the beam has a greater ability to absorb energy during a collision. A mathematical equation for EA is,

$$
\mathrm{EA}=\int_{0}^{\delta} F(x) \cdot d x
$$

Where $\mathrm{F}(\mathrm{x})$ is the crash force, $\delta$ is the deformation of beam.

The SEA indicator measures the amount of energy absorbed per unit mass of the impact beam, and thus it reflects the structure's efficiency. A mathematical equation for SEA is,

$$
\mathrm{SEA}=\frac{E A}{\text { Mass of beam }}
$$

$\mathrm{F}_{\text {avg }}$ is the average value of crash force during the whole bending process, and $\mathrm{F}_{\max }$ is the maximum force during the bending process. The ratio of average force to maximum force is called Crash Force Efficiency, which indicates the steadily of collision process $[7,9,16]$. Thus,

$$
\mathrm{CFE}=\frac{F_{\text {avg }}}{F_{\max }}
$$

In order to achieve better bending performance, weight efficiency, and energy absorption capacity, TWBs have attracted the interest of researchers. The crashworthiness of TWB is influenced by thickness, material, loading angle, and cross-section of the beam. Of these, beam thickness has the greatest impact crashworthiness Maduliat, et al. [15]; Sofi, et al. [16]; Bilston, et al. [17]. Saadatfard, et al. [9] from experimental and numerical results illustrate that by increasing the wall thickness, the EA of the beam will increase. In order to improve the crashworthiness of tubes, some researchers have used hybrid mechanisms. A functionally graded thickness tube is used by Guangyao, et al. [18]. The experimental and numerical results show that the FGT tube absorbs more energy than the uniform thickness tube. Ghadianlou and Abdullah [19] applied various rib arrangements to the side door beams to improve the crashworthiness. Lee, et al. [7] applied formfilled material to improve the crashworthiness of the beam. Different cross-section beams were studied by some researchers in order to compare their crashworthiness. The rectangular cross-section has greater CFE than the square section, but the square section has better SAE than the rectangular section, according to Saadatfard, et al. [9]; Lee, et al. [7]; Sofi, et al. [16]; Bilston, et al. [17]; Patil, et al. [20]. The studies of Tang, et al. [21] show in a comparison of circular, rectangular, and trapezoidal cross-section beams, the elliptical beam has better SEA and CFE. To the author's best knowledge, in available literature, less exposure has been observed in the modification of polygonal cross-section TWBs. In this paper, the bending collapse behaviours of different polygonal cross-sections TWB under lateral impact were investigated through numerical analysis. The weight and thickness of TWB will influence crashworthiness, so in order to compare the crash performance of various beams, the thickness and weight are kept the same for all beams. The numerical simulations were performed using ABAQUS explicit dynamic software. The crashworthiness indicators are used to compare the performance of various beams. The numerical simulation setup has been validated with reported literature experimental results.

\section{Materials and Methods}

In order to analyze the crashworthiness of various polygons, explicit dynamic simulations are performed and crashworthiness indicators are evaluated to study the performance of the beam.

\subsection{Geometry and Material of Polygonal TWB}

All polygon profiles have a thickness of $2 \mathrm{~mm}$, and the weight of all polygons is maintained fixed at $2.14 \mathrm{~kg}$ by adjusting the edge length of the polygon. The dimensions of all polygons are shown in Table 1 . Where ' $L$ ' is the length of the edge and ' $\mathrm{O}$ ' is the outer radius of the polygon. 
Table-1.

Dimension of polygon.

\begin{tabular}{|c|c|c|c|c|}
\hline Profile No. & Name of polygon & $\mathbf{L}(\mathbf{m m})$ & $\mathbf{O}(\mathrm{mm})$ & Geometry \\
\hline POLY 4 & Square & 31.84 & -- & \\
\hline POLY 5 & Pentagon & 30.56 & 26 & \\
\hline POLY 6 & Hexagon & 24 & 24 & \\
\hline POLY 7 & Heptagon & 19.96 & 23 & \\
\hline POLY 8 & Octagon & 16.64 & 22 & \\
\hline POLY 9 & Nonagon & 14.84 & 21.7 & \\
\hline POLY 10 & Decagon & 13.17 & 21.3 & \\
\hline POLY 11 & Hendecagon & 11.87 & 21.05 & \\
\hline POLY 12 & Dodecagon & 10.84 & 20.85 & \\
\hline CIR & Circular & - & 20 & \\
\hline
\end{tabular}

The polygonal tubes are modeled from A36 steel material. For the simulation, the Johnson-Cook material model was selected and the values of its parameters are adopted from the literature [22] and shown in Table 2.

Table-2.

A36 Johnson-Cook material model parameters.

\begin{tabular}{l|l|l}
\hline Parameter & Value & Description \\
\hline $\mathrm{A}$ & $146.7 \mathrm{MPa}$ & Material parameter \\
\hline $\mathrm{B}$ & $896.9 \mathrm{MPa}$ & Material parameter \\
\hline $\mathrm{N}$ & 0.320 & Strain power coefficient \\
\hline $\mathrm{C}$ & 0.323 & Material parameter \\
\hline$\dot{\varepsilon} \rho$ & $1.0 \mathrm{~s}-{ }^{1}$ & Temperature power coefficient \\
\hline$\rho$ & $7850 \mathrm{~kg} / \mathrm{m}^{3}$ & Reference stain rate \\
\hline $\mathrm{Tm}$ & $1773 \mathrm{~K}$ & Density \\
\hline $\mathrm{Cp}$ & $486 \mathrm{~J} / \mathrm{kg}^{\circ}{ }^{\circ} \mathrm{K}$ & Specific heat \\
\hline
\end{tabular}




\subsection{Numerical Simulation Setup}

As the excitation frequency is more than the natural frequency of the structure, numerical simulation is performed in the ABAQUS explicit dynamic module. The systematic and geometry parameters of the simulation setup are shown in Figure 1 and Table 3, respectively, where ' $\mathrm{d}$ ' is the outer diameter of hollow beams, the thickness of the beam is ' $\mathrm{t}$ ', and ' $\mathrm{l}$ ' is the length of the beam. The beam is supported by a cylindrical support of diameter ' $r$ ' with a span ' $s$ '. At the mid-span of the beam, a cylindrical impactor of diameter ' $R$ ' and mass ' $M$ ' is impacted circumferentially on the beam with a velocity of ' $\mathrm{V}$ '.

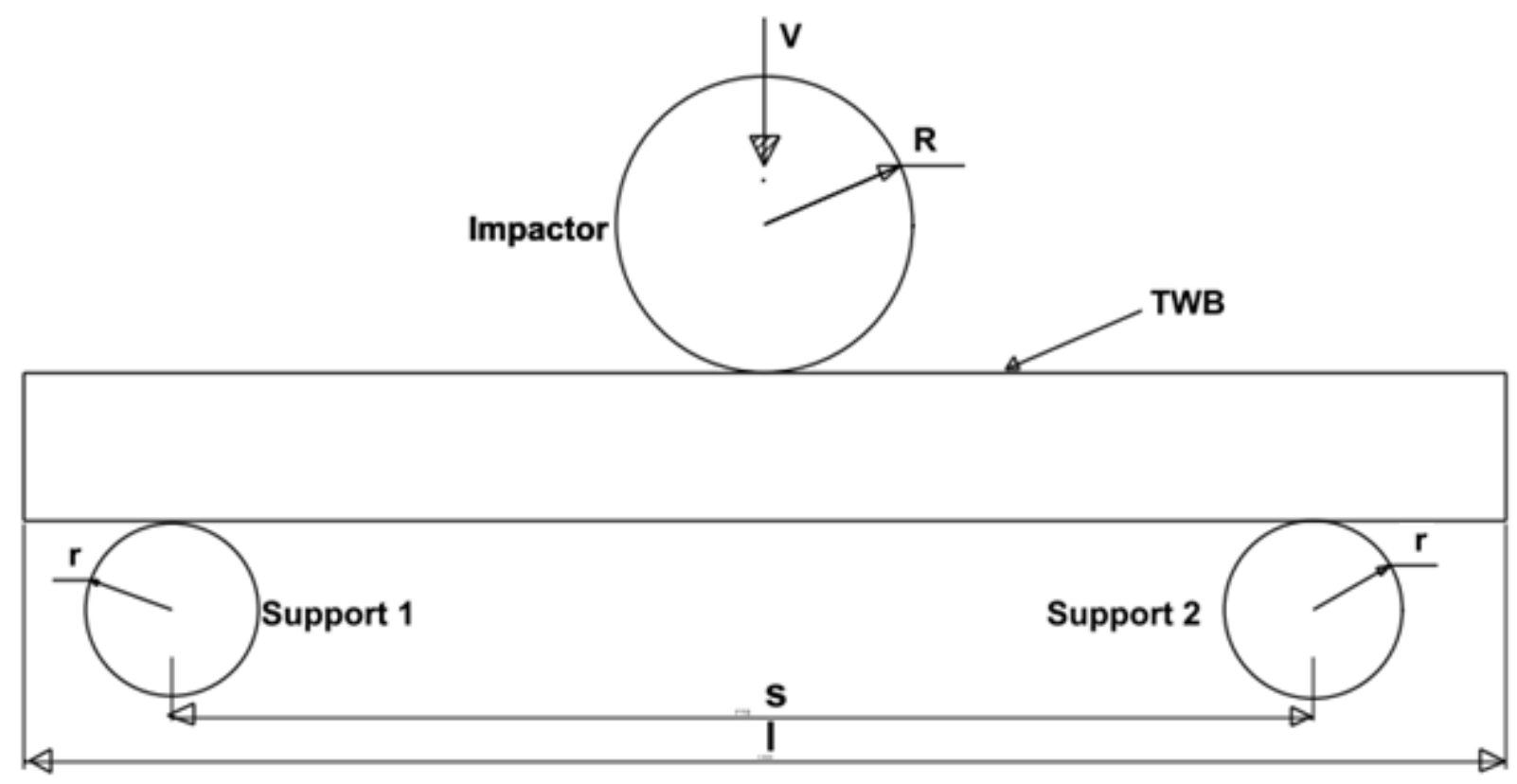

Figure-1.

Systematic of simulation setup.

Table-3.

Simulation properties.

\begin{tabular}{c|c|c|c|c|c|c}
\hline $\mathbf{l}(\mathbf{m m})$ & $\mathbf{S}(\mathbf{m m})$ & $\mathbf{R}(\mathbf{m m})$ & $\mathbf{r}(\mathbf{m m})$ & $\mathbf{M}(\mathbf{k g})$ & $\mathbf{t}(\mathbf{m m})$ & $\mathbf{d}$ \\
\hline 500 & 400 & 100 & 50 & 200 & 2 & 40 \\
\hline
\end{tabular}

The impactor and supports are treated as rigid bodies, whereas the beam is treated as a shell body with a thickness of 2 $\mathrm{mm}$. For the impactor, one direction translation displacement is allowable and for supports, all degrees of freedom are fixed. The impactor and supports are considered as rigid bodies, while the beam is taken as a shell body having a 2 mm thickness. A coefficient of friction of 0.2 is considered at all surface to surface contacts between the impactor, beam and support. In ABAQUS, the 'All with self' surface friction pair is used to avoid interpenetration of surfaces during beam bending. The impact velocity of the impactor is $5.8 \mathrm{~m} / \mathrm{s}$ with a lumped mass of $200 \mathrm{~kg}$. After mesh convergence analysis, the mesh size of the tube has been set at $2 \mathrm{~mm}$, and the mesh size of the impactor and support is set at $10 \mathrm{~mm}$. For all simulations, a four-node shell continuum (S4R) element with five integration points is used. The impactor has a $200 \mathrm{~mm}$ displacement. Figure 2 shows the finite element model of the CIR profile.

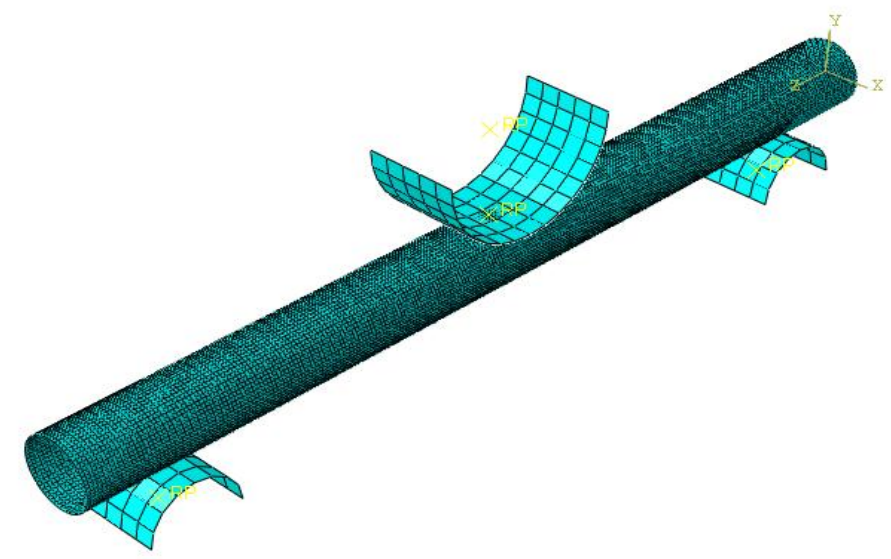

Figure-2.

Numerical simulation model. 


\subsection{Validation of Simulation Setup}

Before studying the analysis of the crashworthiness indicators of various profiles, the numerical simulation results are compared with experimental results published by Tang, et al. [21]. In this literature, a three point bending test was carried out on a circular tube having a $28 \mathrm{~mm}$ diameter and a $2 \mathrm{~mm}$ thickness. The tube is made of AISI1080 material. The impactor's mass and velocity are $148 \mathrm{~kg}$ and $3.4 \mathrm{~m} / \mathrm{s}$, respectively. To compare the numerical results of this study with the experimental results of Tang, et al. [21] numerical simulation was performed using Tang, et al. [21] experimental setup and both results are shown in Figure 3. The experimental results of literature [21] are closely similar with simulation result, the absolute error between them is less than $7 \%$ so this simulation setup is considered for further studies.

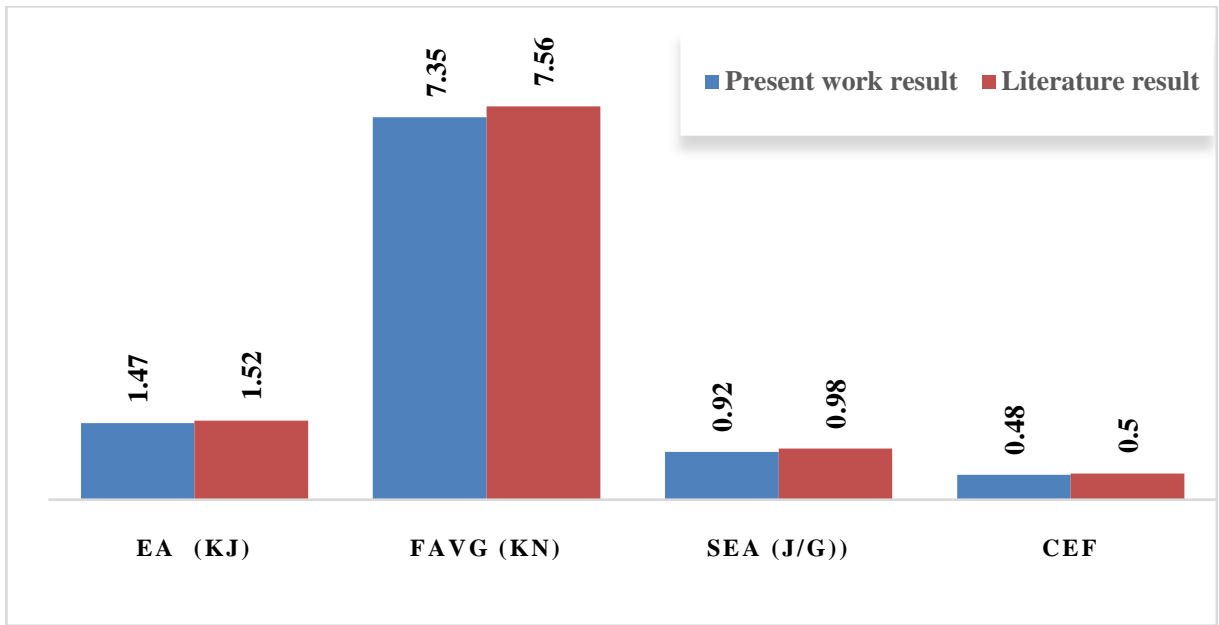

Figure-3.

Numerical v/s experimental result of Tang, et al. [21].

\section{Results and Discussion}

The crashworthiness indicators are listed in Table 4 and are evaluated using Equations 1, 2, and 3. EA, SEA, CFE crashworthiness indicators of all profiles are discussed in the following subsection.

Table-4.

Crashworthiness indicators.

\begin{tabular}{c|c|c|c|c|c}
\hline Profile Name & EA $(\mathbf{k J})$ & SEA $(\mathbf{k J} / \mathbf{k g})$ & $\mathbf{F}_{\text {avg }}(\mathbf{k N})$ & $\mathbf{F}_{\max }(\mathbf{k N})$ & $\mathbf{C F E}$ \\
\hline POLY 4 (square) & 1.796 & 0.8384 & 8.984 & 16.469 & 0.545 \\
\hline POLY 5 & 1.825 & 0.8517 & 9.126 & 19.450 & 0.469 \\
\hline POLY 6 & 1.373 & 0.6410 & 6.869 & 15.030 & 0.457 \\
\hline POLY 7 & 1.433 & 0.6828 & 7.316 & 11.341 & 0.645 \\
\hline POLY 8 & 1.572 & 0.7345 & 7.871 & 12.754 & 0.617 \\
\hline POLY 9 & 1.600 & 0.7468 & 8.003 & 12.190 & 0.656 \\
\hline POLY 10 & 1.377 & 0.6427 & 5.887 & 11.444 & 0.514 \\
\hline POLY 11 & 1.311 & 0.6117 & 5.410 & 11.433 & 0.474 \\
\hline POLY 12 & 1.311 & 0.6117 & 6.555 & 11.879 & 0.552 \\
\hline CIR (Circle) & 1.228 & 0.5732 & 6.143 & 10.587 & 0.580 \\
\hline
\end{tabular}

\subsection{Maximum Crash Force $\left(F_{\max }\right)$ and Force-Displacement Characteristics}

Figures 4, 5, and 6 illustrate the force displacement diagrams of profiles POLY 4, 5, 6, profiles POLY 7, 8, and 9, and profiles POLY 10, 11, 12, CIR, respectively, for ease of discussion. A bending and cross-section flattening pattern of all profiles at simulation frame 15 are shown in Figure 7.

The general characteristics of force-displacement curves for all profiles are similar, but their collapse modes are very different. As profiles in Figure 4 give more resistance to flattening, while profiles in Figure 6 can flatten with less resistance. The results can also be observed in Figures 4, 6, and 7. From Figure 4 and 6, it is seen that for profiles POLY 4, 5 and 6 , the crash force peak value $\left(\mathrm{F}_{\max }\right)$ is larger than for profiles PLOY 11, 12, and CIR. While the crash peak force of profiles shown in Figure 5 is in between the profiles in Figure 4 and 6. The crash force achieves an initial peak as a result of the profile's resistance to flattening, when plastic hinges start to form on edges or corners of polygon the crash force drops and then fluctuates due to the folding of profile edges. 


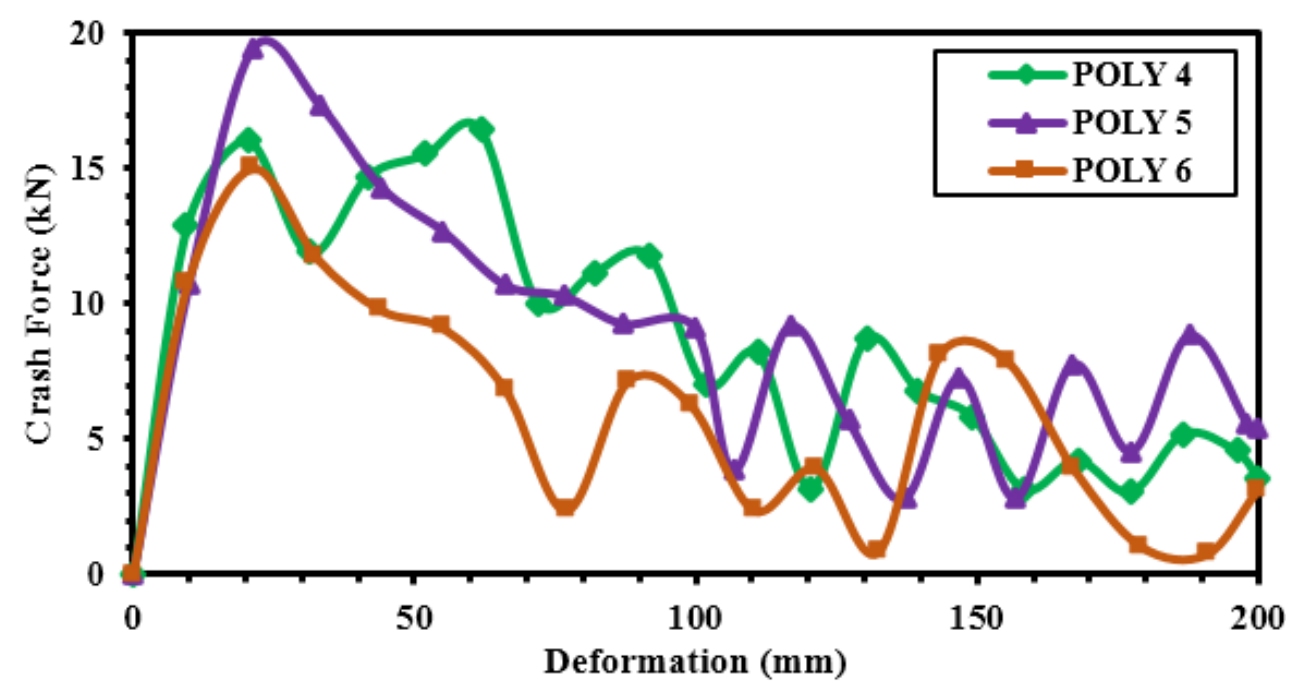

Figure-4.

Force- Disp. curve of Profile POLY 4, 5 and 6.

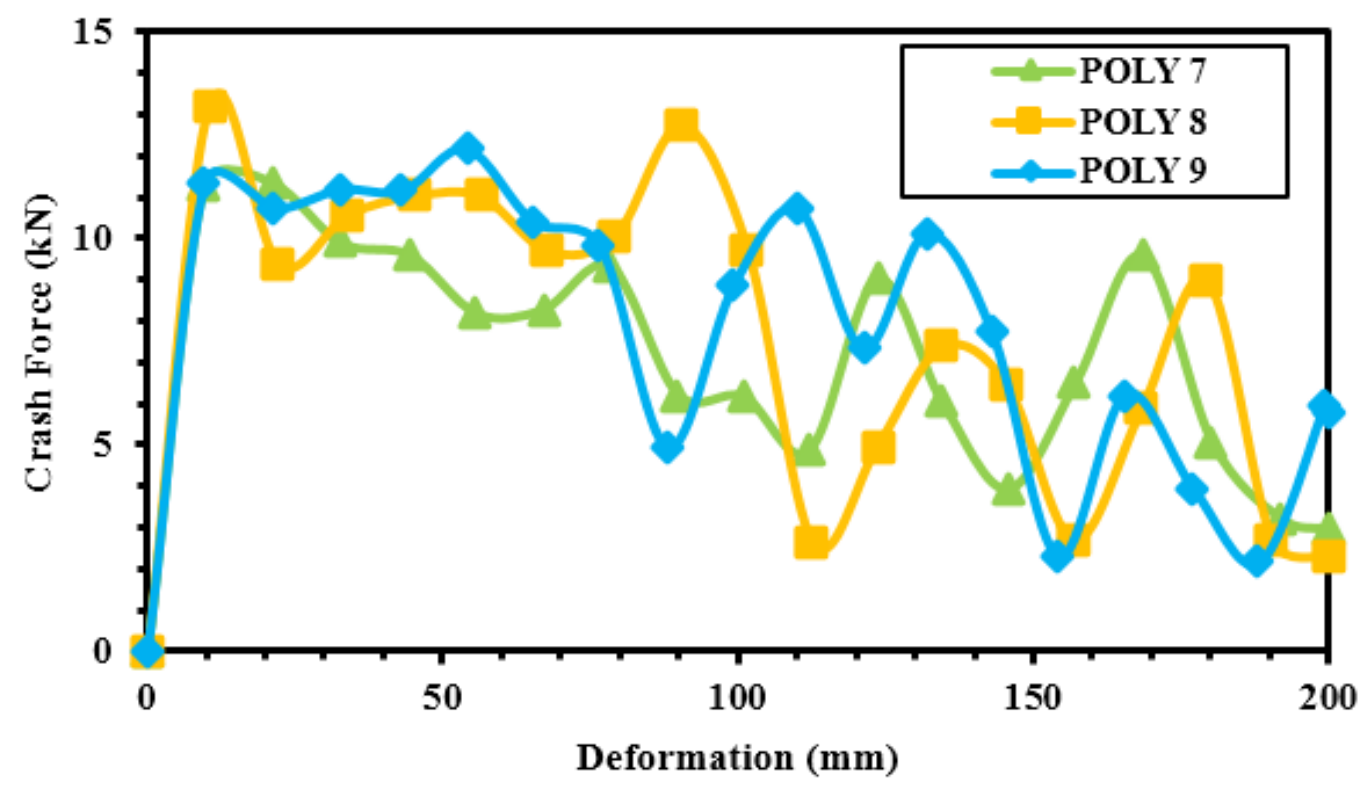

Figure-5.

Force- Disp. curve of Profile POLY 7, 8 and 9.

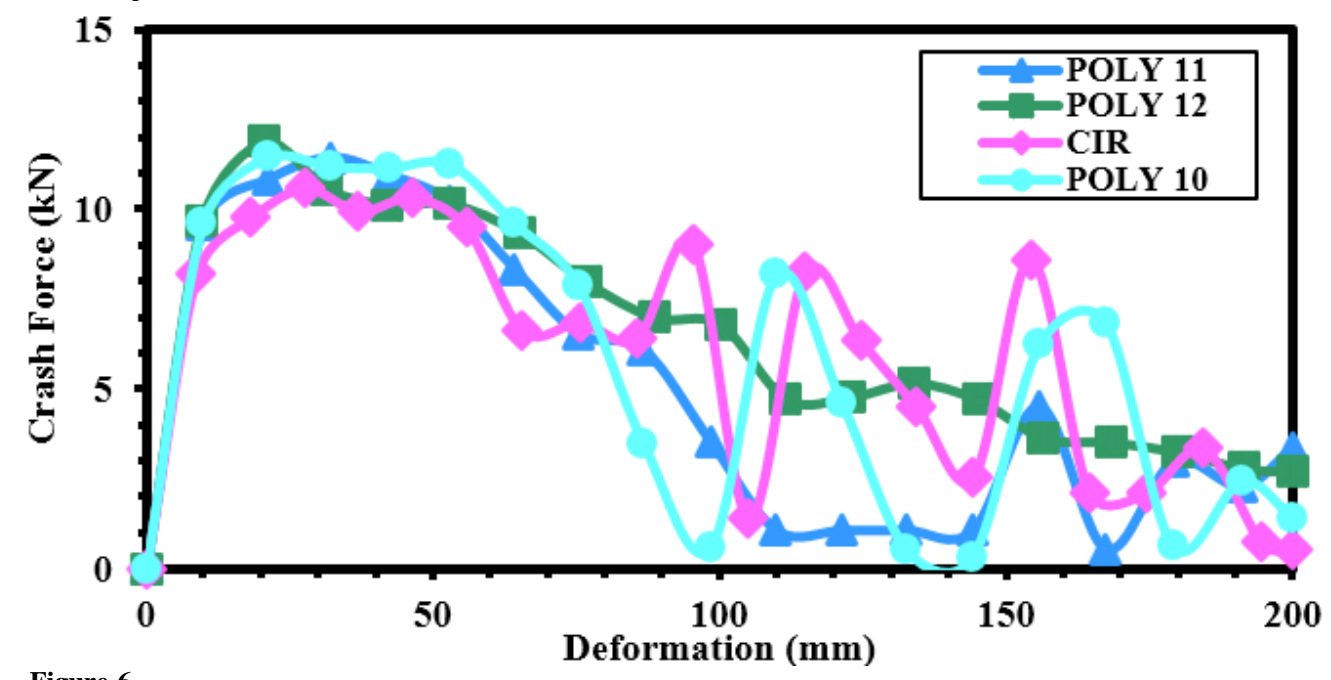

Figure-6.

Force- Disp. curve of Profile POLY 10, 11, 12 and CIR. 


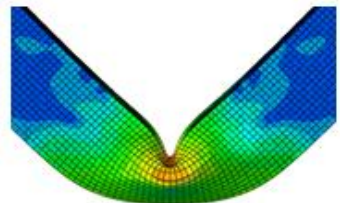

a. Profile POLY 4

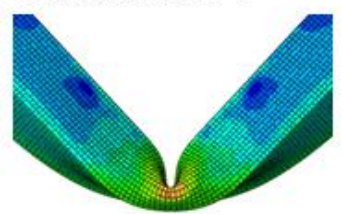

b. Profile POLY 5

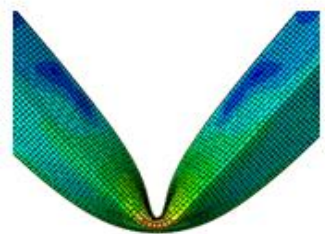

c. Profile POLY 6

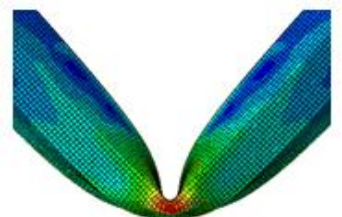

d. Profile POLY 7

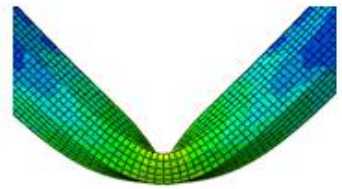

e. Profile POLY 8

Figure-7.

Bending and cross-section flattening pattern of beams at frame 15 .
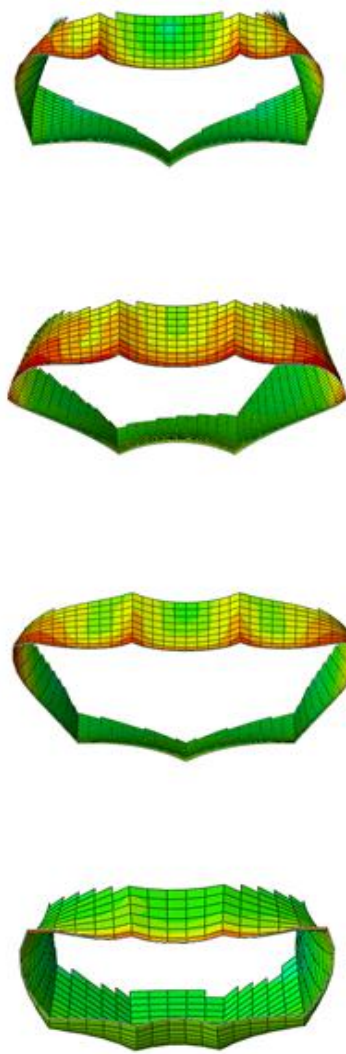
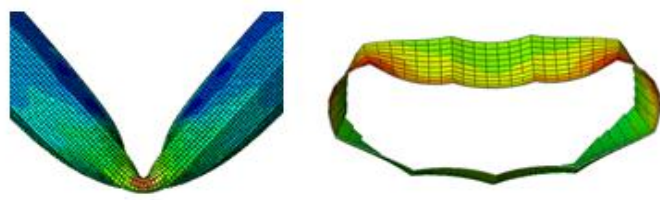

f. Profile POLY 9
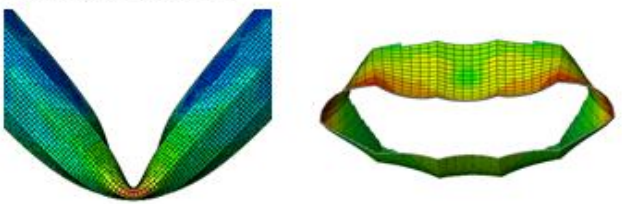

g. Profile POLY 10
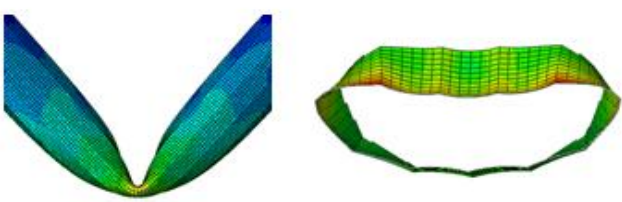

h. Profile POLY 11
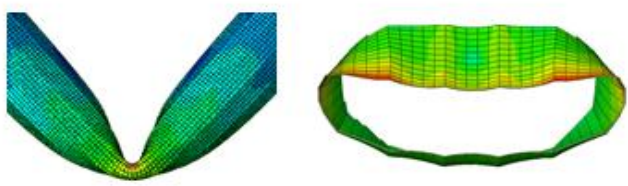

i. Profile POLY 12
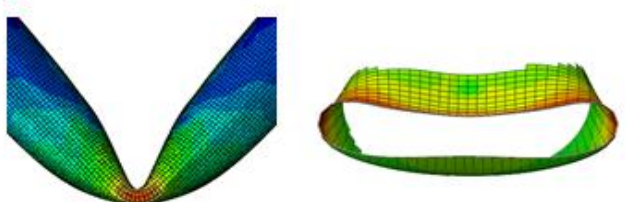

j. Profile CIR

\subsection{Energy Absorption (EA)}

The energy absorption of all profiles is shown in Figure 8. The largest energy absorption capacity of 1.825 and $1.796 \mathrm{~kJ} / \mathrm{kg}$ is seen in the POLY 4 and POLY 5 profile TWB respectively, while the CIR profile has the lowest energy absorption capacity of $12.28 \mathrm{~kJ} / \mathrm{kg}$. From the figures, it can also be observed that the EA for CIR, POLY11, and POLY12 is approximately equal. As stated in section 3.1, plastic hinges drive the bending performance of the beam. It can be seen in Figure 7 that plastic hinges are created along the sides of profiles POLY 4 and 5, so they provide further resistance and absorb greater energy during bending, whereas plastic hinges are created at the corner of polygons for profiles CIR, POLY11 and 12, so they can offer less resistance and absorb less energy during bending.

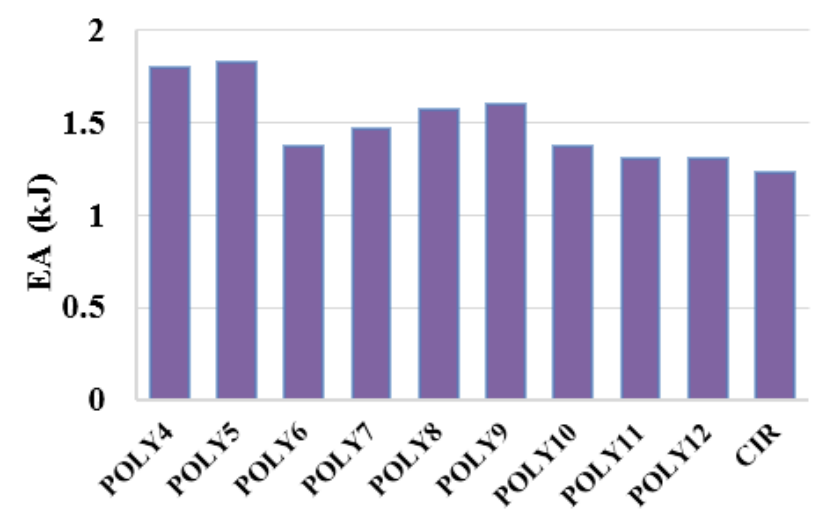

Figure-8.

\section{Profile Name}

Energy Absorption of beams. 


\subsection{Specific Energy Absorption (SEA)}

Figure 9 shows the SEA value for each profile. From figure, the POLY 4 and 5 profiles have larger SEA, while CIR, POLY 11 and 12 have less SEA. SEA indicates the energy absorbed per unit mass of the beam. The EA indicator is described in section 3.2, EA values of profiles PLOY 4 and PLOY 5 are more and profiles CIR, PLOY 11, and PLOY 12 are less. As the mass of each profile is kept the same, these profiles show SEA indicator values in-line with the EA values. The greater value of the SEA indicator implies that the structure is more efficient, consequently POLY 4 and 5 are more efficient. Whereas profiles POLY 9 and 10 have moderate efficiency, and profiles POLY 11, 12, CIR profiles have lower efficiency.

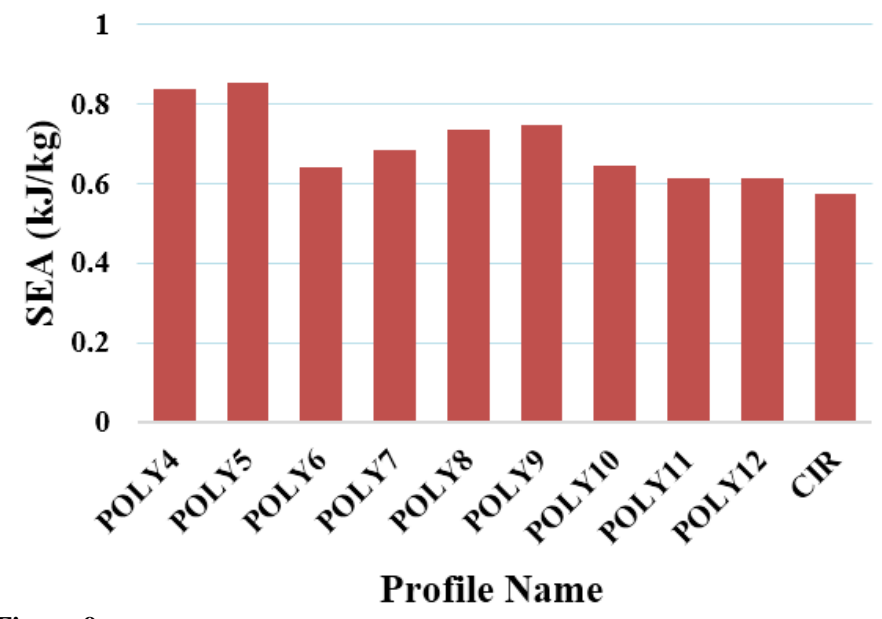

Figure-9.

Specific Energy Absorption of beams.

\subsection{Crash Force Efficiency (CFE)}

Figure 10 shows the CFE of each profile. As the CFE indicator shows steadily of bending collapse. The CFE indicator has a range of 0 to 1 . The crash force of a beam with a CFE value near to 0 is initially higher but rapidly declines in the bending process. As a result, the energy absorption capacity is greater at the start of the bending process and decreases as the deformation of the beam increases. Therefore, a lower CFE indicator is undesirable. When the CFE indicator is close to 1 , it means that the energy absorption capacity of the beam does not degrade significantly as it deforms.

The force-displacement curve shown in Figure 4, for POLY 4, 5 and 6 profiles, the crash force reaches a maximum level, and when plastic hinges are starts to form around one of the edge or corner of the polygon, the crash force is considerably reduced. The flattening pattern of these profiles is shown in Figure 7. Finally, the $\mathrm{F}_{\text {avg }}$ of the entire bending process is much lower than $F_{\max }$. As a result, the CFE indicator is lower. POLY 5 has a CFE of 0.469, which is the lowest among the profiles.

Figure 5 shows the force-displacement curve of profiles POLY 7, 8, and 9. It can be seen that the crash force is comparatively more stable. From the cross-section flattening pattern of these curves shown in Figure 7, it is observed that the plastic hinges gradually produce more than one number of edge and corner polygon, so the crash force of these profiles is more stable than profiles POLY 4, 5 and 6. Finally, the gap between $F_{\text {avg }}$ and $F_{\max }$ is smaller, and the CFD of these profiles is larger than that of others. POLY 9 has a CFE of 0.649, which is the highest among the profiles.

The CFE values for profile PLOY 10,11,12, and CIR are in between the above two cases. These profiles have a crosssection flattening pattern similar to POLY 7, 8, and 9. However, as the number of edges on a polygon increases, the length of each edge grows smaller. As a result, these profiles have lower resistance than POLY 7, 8, and 9.

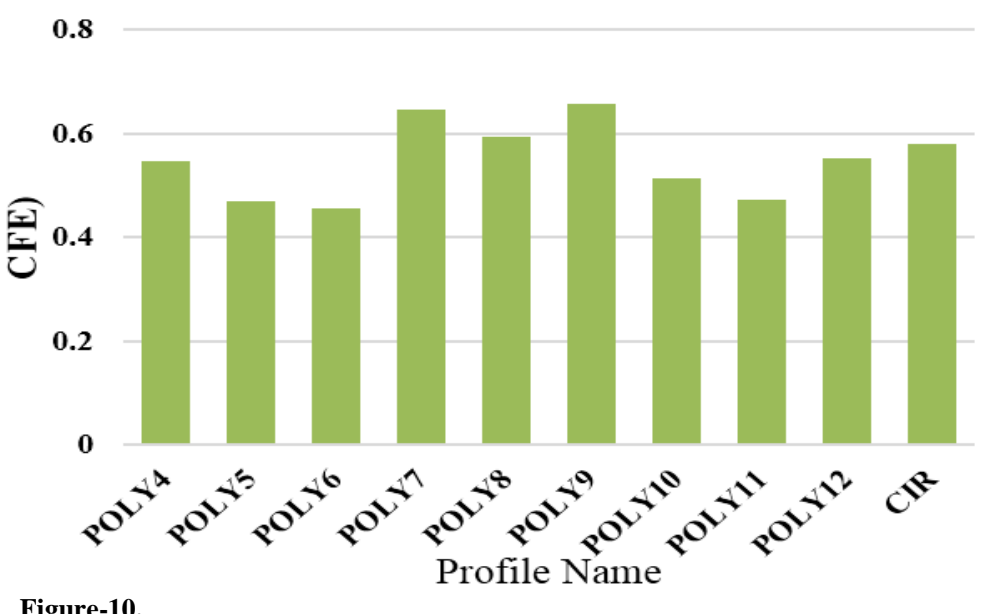

CFE of beams. 


\section{Conclusion}

In this work, the crashworthiness of a polygonal cross-section beam is studied by numerical simulation. The development of plastic hinges and the cross-section flattering pattern of the beam have significantly impacted on crashworthiness indicators. To compare the performance of beams, EA, SEA, and CFE crashworthiness indicators are used and the thickness and weight of the beam are kept constant. Beams with higher SEA and CFE values have superior bending capability.

- In comparison, the EA and SEA values of the square and pentagon are higher because they have fewer edges and hence produce better deformation resistance. Once plastic hinges start developing, their bending resistance decreases drastically and, ultimately, the CFE value of these beams gets lower.

- The bending resistance of hendecagon and dodecagon (POLY 11and 12) profile beams is less due to their shorter edge length. The plastic hinge pattern of these beams is similar to a circular cross-section beam.

- In Heptagon, octagon, and nonagon profile cross-section beams, plastic hinges developed on edges and corners. Hence, they produce better resistance to deformation. The SEA value ranges from 1.4 to $1.6 \mathrm{~kJ} / \mathrm{kg}$ and the $\mathrm{CFE}$ ranges from 0.645 to 0.656 , making them more suitable for crashworthiness applications than similar weight and thickness of circular or square cross-section beams.

\section{References}

[1] J. Luzon-Narro, C. Arregui-Dalmases, L. M. Hernando, E. Core, A. Narbona, and C. Selgas, "Innovative passive and active countermeasures for near side crash safety," International Journal of Crashworthiness, vol. 19, pp. 209-221, 2014.Available at: https://doi.org/10.1080/13588265.2013.802938.

[2] C. Long, S. Yuen, and G. Nurick, "Analysis of a car door subjected to side pole impact," Latin American Journal of Solids and Structures, vol. 16, p. e226, 2019.Available at: https://doi.org/10.1590/1679-78255753.

[3] G. Zhang, F. Yu, Z. OuYang, and H. Chen, "Study on vehicle collision predicting using vehicle acceleration and angular velocity of brake pedal," SAE Technical Paper No. 2015-01-14052015.

[4] M. A. Shaharuzaman, S. M. Sapuan, M. R. Mansor, and M. Y. M. Zuhri, "Passenger car's side door impact beam: A review," Journal of Engineering and Technology, vol. 9, 2018.

[5] J.-H. Yang, "Optimization of the aluminum door impact beam considering the side door strength and the side impact capability," Journal of the Korea Academia-Industrial Cooperation Society, vol. 12, pp. 2025-2030, 2011.Available at: https://doi.org/10.5762/kais.2011.12.5.2025.

[6] B. Watson and D. S. Cronin, "Side impact occupant response with varying positions," International Journal of Crashworthiness, vol. 16, pp. 569-582, 2011.Available at: https://doi.org/10.1080/13588265.2011.616079.

[7] H. Lee, M. Huh, S. Kang, and S. I. Yun, "Compressive behavior of automotive side impact beam with continuous glass fiber reinforced thermoplastics incorporating long fiber thermoplastics ribs," Fibers and Polymers, vol. 18, pp. 1609-1613, 2017.Available at: https://doi.org/10.1007/s12221-017-6927-z.

[8] W. Abramowicz, "Simplified crushing analysis of thin-walled columns and beams," Engineering Hearings, vol. 29, pp. 5-26, 1981.

[9] H. Saadatfard, A. Niknejad, G. Liaghat, and S. Hatami, "A novel general theory for bending and plastic hinge line phenomena in indentation and flattening processes," Thin-Walled Structures, vol. 136, pp. 150-161, 2019.Available at: https://doi.org/10.1016/j.tws.2018.12.007.

[10] D. Kecman, "Bending collapse of rectangular and square section tubes," International Journal of Mechanical Sciences, vol. 25, pp. 623-636, 1983.Available at: https://doi.org/10.1016/0020-7403(83)90072-3.

[11] S. Poonaya, U. Teeboonma, and C. Thinvongpituk, "Plastic collapse analysis of thin-walled circular tubes subjected to bending," Thin-Walled Structures, vol. 47, pp. 637-645, 2009.Available at: https://doi.org/10.1016/j.tws.2008.11.005.

[12] M. Elchalakani, X. L. Zhao, and R. H. Grzebieta, "Plastic mechanism analysis of circular tubes under pure bending," International Journal of Mechanical Sciences, vol. 44, pp. 1117-1143, 2002.Available at: https://doi.org/10.1016/s00207403(02)00017-6.

[13] H. S. S. Aljibori, H. F. A. Al-Qrimli, R. Ramli, E. Mahdi, F. Tarlochan, and W. Chong, "A comparative analysis of experimental and numerical investigations of composite tubes under axial and lateral loading," Australian Journal of Basic and Applied Sciences, vol. 4, pp. 3077-3085, 2010.

[14] M. Kotelko, T. H. Lim, and J. Rhodes, "Post-failure behaviour of box section beams under pure bending (an experimental study)," Thin-Walled Structures, vol. 38, pp. 179-194, 2002.Available at: https://doi.org/10.1016/s0263-8231(00)00032-x.

[15] S. Maduliat, T. D. Ngo, P. Tran, and R. Lumantarna, "Performance of hollow steel tube bollards under quasi-static and lateral impact load," Thin-Walled Structures, vol. 88, pp. 41-47, 2015.Available at: https://doi.org/10.1016/j.tws.2014.11.024.

[16] M. Sofi, Z. Chow, K. Wong, and Z. Ahmad, "Study of multi-cell thin-walled tube with various configuration under lateral loading," in IOP Conference Series: Materials Science and Engineering, 2020, p. 012086.

[17] D. Bilston, D. Ruan, A. Candido, and Y. Durandet, "Parametric study of the cross-section shape of aluminium tubes in dynamic three-point bending," Thin-Walled Structures, vol. 136, pp. 315-322, 2019.Available at: https://doi.org/10.1016/j.tws.2018.12.032.

[18] L. Guangyao, X. Fengxiang, S. Guangyong, and L. Qing, "Crashworthiness study on functionally graded thin walled structures," International Journal of Crashworthiness, vol. 20, pp. 280-300, 2015.Available at: https://doi.org/10.1080/13588265.2015.1010396.

[19] A. Ghadianlou and S. B. Abdullah, "Crashworthiness design of vehicle side door beams under low-speed pole side impacts," Thin-Walled Structures, vol. 67, pp. 25-33, 2013.Available at: https://doi.org/10.1016/j.tws.2013.02.004.

[20] S. D. Patil, V. Y. Dhepe, D. S. Lengare, A. J. Bhosale, and R. B. Teltumade, "Parameters of side intrusion beam affecting on crash force efficiency during impact," International Journal of Recent Technology and Engineering, vol. 8, pp. 4524-4529, 2020.Available at: https://doi.org/10.35940/ijeat.c6259.029320. 
[21] T. Tang, W. Zhang, H. Yin, and H. Wang, "Crushing analysis of thin-walled beams with various section geometries under lateral impact," Thin-Walled Structures, vol. 102, pp. 43-57, 2016.Available at: https://doi.org/10.1016/j.tws.2016.01.017.

[22] F. Tarlochan, F. Samer, A. Hamouda, S. Ramesh, and K. Khalid, "Design of thin wall structures for energy absorption applications: Enhancement of crashworthiness due to axial and oblique impact forces," Thin-Walled Structures, vol. 71, pp. 717, 2013.Available at: https://doi.org/10.1016/j.tws.2013.04.003. 